\title{
The Effects of Cultural Dimensions and Hr Practices on Organisational Commitment: An Empirical Evidence from The Telecom Sector Of Pakistan
}

\author{
*Muhammad Zeeshan, **Dr. Hazoor Muhammad Sabir \& \\ ***Dr. Sharjeel Saleem \\ * MS. Scholar, Department of Business Administration, Government College University, Faisalabad, Pakistan. \\ ** Associate Professor, Department of Business Administration, Government College University, Faisalabad, \\ Pakistan. \\ ***Dr. Sharjeel Saleem, PhD Management (Austria), Assistant Professor, Department of Business \\ Administration, Government College University Faisalabad, Pakistan
}

\begin{abstract}
The study was aimed to acquire the effects of cultural dimensions and HR practices on organizational commitment of the fastest growing telecom sector in Pakistan. A questionnaire was used and distributed to 200 correspondents among the telecom sector in the equal ratio and from which 149 were received back. The research tools were collectivism and power distance, rewards, psychological empowerment, performance evaluation and organizational commitment respectively, questionnaires of Dortman and Howell's, Al-Nsour, Spreitzer, Cook and Crossman, and Porter were used. The study revealed that power distance, rewards, psychological empowerment and performance evaluation bore the significant impact, whereas collectivism showed insignificant impact on the organizational commitment
\end{abstract}

Keywords: Collectivism, Power Distance, Rewards, Psychological Empowerment, Performance Evaluation, Organizational Commitment.

\section{Introduction}

From the stone age to this modern era, communication always remains very important in all the aspects, thought it your personal life or your business matters. For the survival of human beings, communication is the basic need to move from one place to another, communication is needed. In this globe, people talk to each other, though the communication mode was different and gradually a slight change took place every time from gestures to sounds, symbols, and your body language to the proper language.

In the absence of language it is very difficult to live in. The signs like Fire and smoke were medium of the communication which is replaced by today's communication medium that is telecommunication. Due to this world becomes global village and the importance of telecommunication cannot left behind. Telecom industry is a booming industry in Pakistan. In the last few years, telecom industry has shown the rapid growth and is among the highly taxed one too collecting large revenue for the country.

An organization is made of employees working to achieve an organization's goal. Employees are important to a business as they are an organization's greatest assets and are an integral part of any business.

Collectivism exists at organizational level it is called as organizational collectivism. We may say that Organization collectivism is an approach which is a group of people (team) within an organization is given a specific task and they work to successfully accomplish their work as a team. It is an approach which develops group cohesiveness, harmony among the group members, enhances team spirit, and increases the avoidance of favoritism and the appraisal of group as a whole(Triandis, 1995).

In organizational cultures that have a great power distance, there will be large distance between the powerful and the low status people. The powerful have all the resources in hand. The subordinates i.e. employees feel that they will tell them what is right and what is not and there is the same situation on the others side. The cultures having high power distant cultures, the attitude like reserve is high. They show their behavior by their dresses, their name titles and the less powerful feel the difference. Conversely, in those organizations where the power distance is low, there we find the low power distance and it's less highlighted (Brockner et al., 2001).

HR practices affect the organizational commitment as a whole. For that 1689 employees sample were taken to see the with the help of Cross-level analyses using hierarchical linear modeling to determine the result (Whitener, 2001). Maddux and Galinsky (2009) conducted a study to evaluate how the cultural dimensions of the collectivistic interaction and organizational rewards influence the organizational commitment and the results obtained through survey showed that there exist a two way interaction between the cultural dimensions of both collectivism and organizational rewards on commitment of the employees. Kuo, Yin, and $\mathrm{Li}$ (2008) conducted a 
study to establish a framework which could be able to explain how to effectively use empowerment to strengthen employee commitment to an organization and further to examine the moderating effects that are caused due to the locus of control and perceived psychological contract breach under changing conditions. For the purpose of this study a questionnaire survey was conducted which included 213 employees at three of Taiwan's state owned enterprises which were undergoing privatization or reorganization. Sial, Jilani, Imran, and Zaheer (2011) conducted a study having a main purpose to probe in the effects of several human resource practices like promotion, performance evaluation and compensation on the commitment shown by the several faculty members of different universities towards their institution. For the purpose of research about 206 teachers were randomly selected from different institutions irrespective of their gender, the race from which they belong to and their designation and were dispensed with questionnaire.

Researchers have found some concepts from the previous studies took place in the developed countries. Many of the studies explain the relationship between cultural dimensions, HR practices and organizational commitment. In Pakistan the cultural dimensions are at the introductory phase. Not much of the people are familiar with the aspects and on the contrary HR practices have got their own worth gradually. Researcher became motivated to know how much these wide terms are giving their output here in Pakistan which is cultural dimensions and HR practices. Organizational commitment is as important to any of the organization as breath and telecom sector is at the boom here in Pakistan, so we have selected all the five organization to have a clear view of the study. This will make a positive add up in the literature of cultural dimensions and HR practices and their impact on the organizational commitment.

Keeping in view the above mentioned effects, the need of following study was sought under the following objectives. It is to examine the effect of cultural dimensions on the organizational commitment and to find out whether HR practices are playing there role to commit their employees in the organizations or vice versa.

\section{Material And Methods}

This chapter describes the general approach and techniques that were used in this study. These include sampling, target population, data collection and the method of data analysis.
Sampling:
In this section our target population discussed here,

Target population: Target population for the research was telecom sector and there we meet with the middle level management to have their feedback about the research topic. This study is restricted to the major companies dealing in the mobile sector having their offices here in Faisalabad. The main aim is to see the employee's commitment against the cultural dimension and HR practices. There are 20 companies working in the telecom sector of Pakistan but only major companies were focused.

Data Collection: The questionnaire was used to collect primary data. Questionnaire is more convenient, because it comprises close ended questions due to which standardized responses obtained. The data collected through the questionnaire could easily compute because Likert scale was used with that to have a clear idea of the respondents(Allen \& Seaman, 2007). Following were the data collection sources in our study:

- $\quad$ Primary data were collected through questionnaire containing Five Point Likert Scale, consisting two parts. The basic information and the questions about variables. There were six variables in the questionnaire, five independent and one dependent variable as show in the figure 1.

$$
\begin{aligned}
& \text { Independent variables include: } \\
& \begin{array}{ll}
\text { - } & \text { Collectivism } \\
\text { - } & \text { Power Distance }
\end{array} \\
& \text { - } \quad \text { Rewards } \\
& \text { - } \quad \text { Psychological Empowerment } \\
& \text { - Performance Evaluation } \\
& \text { Dependent variable includes: } \\
& \text { - } \quad \text { Organizational Commitment }
\end{aligned}
$$

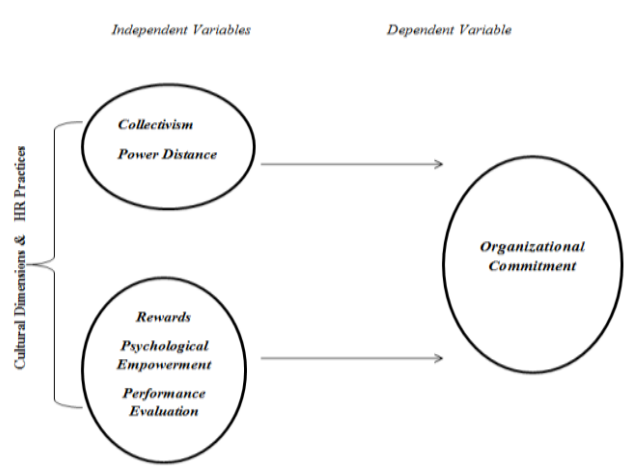

Analytical Technique: The sample data were collected in the form of primary data and the multiple liner regression was applied to check the effects of cultural dimensions and HR practices on the organizational commitment. The association between the dependent and independent variables were observed. The enter method was applied to check the model parameters as used by Meshksar (2012), and Wasti (2003) and results coincides with the present study. 
Statistical Model: A statistical model was used to study the impact of cultural dimensions and HR practices on the organizational commitment. Using liner regression equation shown in Eq. 1

$\boldsymbol{Y}=\boldsymbol{\beta}_{o}+\boldsymbol{\beta}_{1} \boldsymbol{C}+\boldsymbol{\beta}_{2} \boldsymbol{H}+\mathcal{E}$

Where, $\mathrm{Y}$ is the dependent variable representing the organizational commitment. " $\beta_{0}$ " is constant and " $\beta 1$ " is coefficient of explanatory variable of Cultural Dimensions and " $\mathrm{H}$ " is explanatory variable of HR Practices and " $\mathrm{C}$ " error term, supposed to remain constant and have an average (mean) of zero over time. The equation " 1 " can be rewritten as:

$\begin{array}{lll}\text { OCOMT }=\boldsymbol{\beta}_{\boldsymbol{o}}+\boldsymbol{\beta}_{\mathbf{l}} \boldsymbol{C O L C T}+\boldsymbol{\beta}_{2} \boldsymbol{P D S T}+\boldsymbol{\beta}_{3} \boldsymbol{R} \boldsymbol{W R D}+\boldsymbol{\beta}_{4} \boldsymbol{P E M} \boldsymbol{P} \\ \text { Where: } & =\quad \text { Organizational Commitment }() \\ \text { OCOMT } & =\quad \text { Constant } \\ \beta_{o} & \text { Collectivism } \\ \text { COLCT }= & =\quad \text { Power Distance } \\ \text { PDST } & \text { Rewards } \\ \text { RWRD }= & = & \text { Psychological Empowerment } \\ \text { PEMP } & = & \text { Performance Evaluation } \\ \text { PEVA } & = & \text { Error Term }\end{array}$

III. Results \& Discussion

After careful analysis and evaluation of questioners, following were the results obtained from the specific study.

200 questionnaires, 40 each were distributed among the five major Telecommunication companies (Mobilink, Ufone, Waird, Teneor \& Zong) of the Pakistan out of which 149 filled and 51 unfilled questionnaires were collected back comprising $74.5 \%$ and $25.5 \%$ respectively, as shown in figure 2 and 2.(a) represents the questionnaires received from the individual companies under telecom sector.

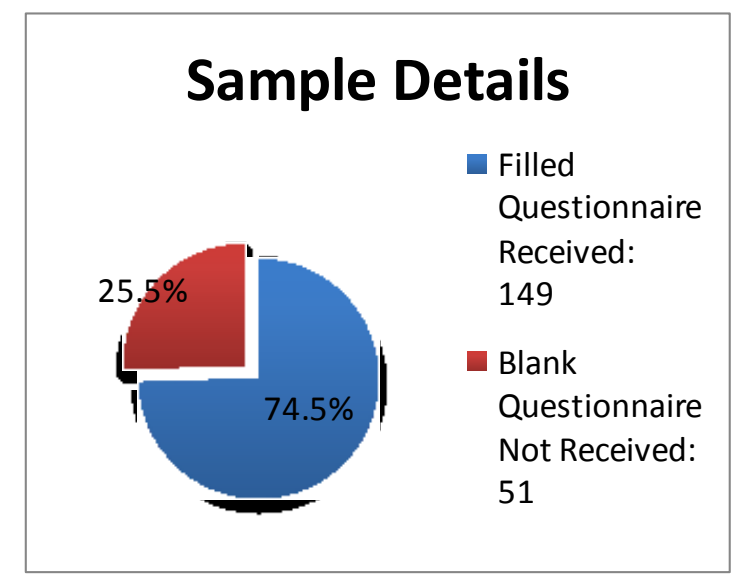

Figure 2: Sample Details

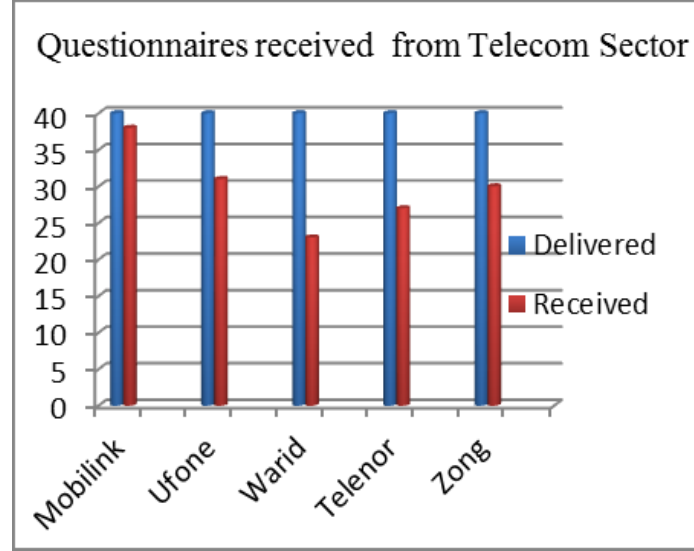

Figure 2(a). Questionnaire received individually

Statistical Analysis: Table 1 showing the means, minimum value and the maximum value of the different variable belongs to the cultural dimension HR practices and organizational commitment.

All these values showed the results of full sample size. The anaylsis given in table 1 shows tha the independent variable COLCT reflects a mean value of 1.8747 followed by $2.2707,1.8842,1.8322,2.0268$ and 2.0779 of PDST, RWRD,, PEMP,PEVA and OCOMT respectively.

Table: 1.

\begin{tabular}{|l|l|l|l|l|l|l|l|}
\hline & & COLCT & PDST & RWRD & PEMP & PEVA & OCOMT \\
\cline { 2 - 8 } & Minimum & 1 & 1.33 & 1.06 & 1.08 & 1 & 1.27 \\
\cline { 2 - 9 } \\
\cline { 2 - 9 } & Maximum & 3.83 & 4.83 & 3 & 3 & 4.14 & 2.87 \\
\cline { 2 - 9 } & Mean & 1.8747 & 2.2707 & 1.8842 & 1.8322 & 2.0268 & 2.0779 \\
\hline
\end{tabular}


OLS Regression Analysis: Table 1 showed the results of OLS Regression Analysis of all the dependent and independent variables.

\begin{tabular}{|l|l|l|}
\hline Model & Coefficients & T \\
\hline (Constant) & $\begin{array}{l}0.696 \\
-0.171\end{array}$ & $4.069^{* * *}$ \\
\hline COLCT & -0.22 \\
& -0.075 & -0.297 \\
\hline PDST & 0.206 & $4.097^{* * *}$ \\
\hline RWRD & -0.05 & $1.770^{*}$ \\
\hline PEMP & -0.155 & $1.946^{*}$ \\
\hline PEVA & 0.177 & $2.627^{* * *}$ \\
\hline
\end{tabular}

Coefficient value of collectivism is -0.22 which indicates that the collectivism is resulting decrease in the organizational commitment. $\mathrm{t}$ value is 0.767 which is showing that it is statistically insignificant. Collectivism has no positive impact on organizational commitment. Power distance is having a positive impact on organizational commitment in full sample. It coefficient value is 0.206 and It is significant at $1 \%$ which is showing the productivity that how it can influence the commitment of the employees towards organization. Rewards have significant impact on organizational commitment. It coefficient value is 0.155 these figurers state that, results are significant at $10 \%$. In other words rewards are playing a role to push employees to remain committed to the organization. Psychological empowerment has also positive impact on organizational commitment. It coefficient value is 0.177 . This value is highly significant at $10 \%$. Performance evaluation in full sample shows that has significant impact of organizational commitment. It coefficient value is 0.168 .It indicates that it significant at $1 \%$.

The results have shown that there are some variables directly effecting the organizational commitment and there are some variable in the favor of organizational commitment. The end results which we received from the data showed that the collectivism has no positive impact on organizational commitment. it is statistically insignificant. it is found that the collectivism could produce the better results if everybody in the group give their best (Wasti, 2003).

The end results which we received from the data showed that the power distance has positive impact on organizational commitment. This is highly significant. (Clugston, Howell, \& Dorfman, 2000) measured that power distance is absolutely associated with the organizational commitment. The results received from the data that the rewards have significant impact on organizational commitment. It is statistically significant. (Erbasi \& Arat, 2012) found the results that the incentives always play a vital role for the commitment of the organization. Psychological empowerments results showed that it has significant impact on organizational commitment. From these results we conclude that Psychological empowerment has also positive impact on organizational commitment. Previous studies showed psychological empowerment plays a roles against the employees commitment (Kotze, Mthembu, \& Khashane, 2007). (Patrick \& Laschinger, 2006) said, increase the empowerment at work place will result a high level of organizational commitment. .Performance evaluation is the third variable took from the head of HR practices and last variable of the study. The end results which we received from the data showed that the performance evaluation have significant impact on organizational commitment. On the basis of these results we conclude that, performance evaluation has significant impact of organizational commitment. (Williams \& Anderson, 1991) founded that performance evaluation and organizational commitment are dependent.

\section{Recommendations}

Here are some of the recommendations for future exploration.

Collectivism found in most of the countries, but in Pakistan according to this study the, it was not in practice, whereas, power distance, rewards, psychological empowerment and performance evaluation were the elements which could retain the employees with them.

\section{Conclusions}

HR practices having their importance but gradually cultural dimensions are having their importance too. Collectivism and power distance have become very power full dimensions directly affecting the 
organizational behaviours. Though some of the people don't know about such practices but they are part of that. Management has to take some serious decisions to have their desired output with the satisfaction of the employees.

\section{References:}

[1]. Allen, I. E., \& Seaman, C. A. (2007). Likert scales and data analyses. Quality Progress, 40(7), 64-65.

[2]. Brockner, J., Ackerman, G., Greenberg, J., Gelfand, M. J., Francesco, A. M., Chen, Z. X., Kirkman, B. L. (2001). Culture and procedural justice: The influence of power distance on reactions to voice. Journal of Experimental Social Psychology, 37(4), 300315 .

[3]. Clugston, M., Howell, J. P., \& Dorfman, P. W. (2000). Does cultural socialization predict multiple bases and foci of commitment? Journal of management, 26(1), 5-30.

[4]. Erbasi, A., \& Arat, T. (2012). The Effect of Financial and Non-financial Incentives on Job Satisfaction: An Examination of Food Chain Premises in Turkey. International Business Research, 5(10), p136.

[5]. Kotze, E., Mthembu, O., \& Khashane, E. (2007). Psychological empowerment in the military: the role of gender and race. Journal of Public Administration, 42(8), 786-797.

[6]. Kuo, H. T., Yin, T. J. C., \& Li, I. (2008). Relationship between organizational empowerment and job satisfaction perceived by nursing assistants at long-term care facilities. Journal of clinical nursing, 17(22), 3059-3066.

[7]. Maddux, W. W., \& Galinsky, A. D. (2009). Cultural borders and mental barriers: the relationship between living abroad and creativity. Journal of personality and social psychology, 96(5), 1047.

[8]. Meshksar, S. (2012). A Comparative Study of HRM Practices Based on Hofstede Cultural Dimensions. Eastern Mediterranean University (EMU).

[9]. Patrick, A., \& Laschinger, H. K. S. (2006). The effect of structural empowerment and perceived organizational support on middle level nurse managers' role satisfaction. Journal of Nursing Management, 14(1), 13-22.

[10]. Sial, M. A., Jilani, S. M. A., Imran, R., \& Zaheer, A. (2011). Effect of Human Resources Practices on Organizational Commitment in Pakistani Universities. World Applied Science Journal, 45, 587-597.

[11]. Triandis, H. C. (1995). Individualism \& collectivism: Westview Press.

[12]. Wasti, S. A. (2003). Organizational commitment, turnover intentions and the influence of cultural values. Journal of Occupational and Organizational Psychology, 76(3), 303-321.

[13]. Whitener, E. M. (2001). Do "high commitment" human resource practices affect employee commitment? A cross-level analysis using hierarchical linear modeling. Journal of management, 27(5), 515-535.

[14]. Williams, L. J., \& Anderson, S. E. (1991). Job satisfaction and organizational commitment as predictors of organizational citizenship and in-role behaviors. Journal of management, 17(3), 601-617. 